Short Communication

\title{
Electrochemical Analysis of Passivation Film Formation on Steel Rebar in Concrete
}

\author{
Xiaoyu Shang ${ }^{*}$, Youjia Zhang, Na Qu and Xiaocheng Tang \\ Department of Civil Engineering, Northeast Dianli University, Jilin, 132012, P.R. China \\ *E-mail: shangxiaoyu@nedu.edu.cn
}

doi: $10.20964 / 2016.07 .44$

Received: 19 March 2016 / Accepted: 14 May 2016 / Published: 4 June 2016

\begin{abstract}
In this article, the passivation film of rebar was formed using cyclic voltammetry (CV) on reinforced concrete. The detail composition of the passivation film was analyzed by X-ray photoelectron spectroscopy. The electrochemical properties of the passivation film formed using the CV method were compared with the naturally formed passivation film. Study showed the properties of the passivation film could be affected by the chloride ions concentration and the electrolyte $\mathrm{pH}$ value. More oxidized passivation film could be formed when the presence of the chloride ions. Meanwhile, the decreasing of the $\mathrm{pH}$ value could enhance the content of chromium in the film and reduce the magnetite.
\end{abstract}

Keywords: Reinforced concrete; Corrosion; Cyclic voltammetry; Electrochemistry; XPS; Passivation film

\section{$\underline{\text { FULL TEXT }}$}

(C) 2016 The Authors. Published by ESG (www.electrochemsci.org). This article is an open access article distributed under the terms and conditions of the Creative Commons Attribution license (http://creativecommons.org/licenses/by/4.0/). 